\section{Comparative Evaluation of the Effects of Gibberellic Acid Concentrations on Dormancy Break in Tubers of Solanum chacoense}

\author{
Christian T. Christensen ${ }^{1}$, Lincoln Zotarelli ${ }^{1}$, \\ Kathleen G. Haynes ${ }^{2}$, and Charles Ethan Kelly ${ }^{1}$
}

AdDitional INDEX wORDs. potato, sprout number, tuber size

Summary. Solanum chacoense is a wild relative of potato (Solanum tuberosum) that is of interest because of its many desirable traits, but it exhibits variations in tuber dormancy across accessions. The objective of this study was to determine an appropriate gibberellic acid $\left(\mathrm{GA}_{3}\right)$ concentration and soak time treatment to encourage sprout development across four accessions of $S$. chacoense $(\mathrm{A}, \mathrm{B}, \mathrm{C}$, and $\mathrm{D})$ from the 174 accessions of the U.S. Department of Agriculture Potato Genebank. Twelve treatments were created by using four concentrations of $\mathrm{GA}_{3}(0,50,100$, and 150 $\left.\mu \mathrm{g} \cdot \mathrm{mL}^{-1}\right)$ across three soak periods $(5,45$, and 90 minutes). Small (average weight, $1.4 \mathrm{~g})$, medium $(2.6 \mathrm{~g})$, and large $(5.6 \mathrm{~g})$ tubers were distributed among all treatments. Percentage of tubers sprouted, time to sprouting, sprout length, and sprout number per tuber were analyzed to determine the effectiveness of $\mathrm{GA}_{3}$ treatments on dormancy breaking. $\mathrm{GA}_{3}$ concentrations of 50,100 , and $150 \mu \mathrm{g} \cdot \mathrm{mL}^{-1}$ partially broke dormancy within accessions $B$ and $C$. None of the tested treatments were effective for breaking dormancy in accession $D$ within 46 days after treatment. Accession A showed weaker dormancy, thus producing a similar percentage of sprouted tubers across all $\mathrm{GA}_{3}$ treatments. Soak time had no significant effect on all parameters measured. Larger tubers produced greater sprout number per tuber and percentages of sprouted tubers. Soaking tubers in $50 \mu \mathrm{g} \cdot \mathrm{mL}^{-1}$ of $\mathrm{GA}_{3}$ may be an effective treatment for $S$. chacoense accessions with mild dormancy, but alternative methods to break dormancy may be required for $S$. chacoense accessions with stronger dormancy.

S olanum chacoense $(2 n=2 x=24)$ is a wild potato species that is native to South America. It has been evaluated for several traits of interest for future incorporation in commercially produced potato, such as greater root biomass linked to higher nitrogen uptake efficiency (Errebhi et al., 1999, 1998), late blight resistance (Colon and Budding, 1988), salinity tolerance (Bilski et al., 1988), resistance to verticillium wilt [Verticillium dablia (Lynch et al., 1997; Uribe et al., 2014)], resistance to potato virus Y (PVY) [Potyvirus (Sato et al., 2006)],

Received for publication 1 July 2019. Accepted for publication 28 Oct. 2019.

Published online 5 December 2019.

${ }^{1}$ University of Florida, Horticultural Sciences Department, Institute of Food and Agricultural Sciences, 1241 Fifield Hall, Gainesville, FL, 32611

${ }^{2}$ U.S. Department of Agriculture, Agricultural Research Service, Genetic Improvement of Fruits and Vegetables Laboratory, Beltsville, MD 20705

This manuscript was orally presented at the 2019 Annual Meeting of the Florida State Horticultural Society in Maitland, FL.

L.Z. is the corresponding author. E-mail: lzota@ufl.edu.

This is an open access article distributed under the CC BY-NC-ND license (https://creativecommons.org/ licenses/by-nc-nd/4.0/).

https://doi.org/10.21273/HORTTECH04448-19 and potato leafroll virus (PLRV) [Polerovirus (Brown and Thomas, 1993)]. This species also accumulates a number of glycoalkaloid compounds that work as natural deterrents of colorado potato beetle [Leptinotarsa decemlineata (Bamberg et al., 1996; Mweetwa et al., 2011; Sinden et al., 1980)]. S. chacoense naturally produces unreduced gametes (Capo et al., 2002; Leue and Peloquin, 1980), which allows for the transmission of these valuable genes from diploid $S$. chacoense to tetraploid $S$. tuberosum via $4 \mathrm{x}-2 \mathrm{x}$ crosses. However, newly harvested material of $S$. chacoense across populations, also referred to as accessions, has shown uneven dormancy and plant emergence.
Below the surface of the soil, a potato plant produces both roots and stem organs called stolons. Flowering in potato plants generally coincides with the swelling of stolon tips in which a majority of the tuber is formed by randomly oriented cell division and expansion (Jackson, 1999). Deposited in these cells are storage carbohydrates and proteins, including starch and patatin, respectively (Shewry, 2003), making tubers strong storage sink organs (Fernie and Willmitzer, 2001). Coinciding with tuber formation is the onset of dormancy. Dormancy can be described as the halting of all meristematic activity in the stolon apex and nodes (Sonnewald, 2001; Xu et al., 1998), and it serves physiological adaptation by allowing survival during periods of unfavorable conditions (Sonnewald, 2001). According to Suttle (2011), there are three stages of dormancy in potato tubers. The first stage of dormancy is referred to as endodormancy, during which endogenous factors restrict the formation of sprouts even under ideal conditions. The second stage of dormancy is referred to as paradormancy, during which sprouting is restricted by external physiological factors. The third stage of dormancy is referred to ecodormancy, during which meristematic activity is halted by external environmental factors. Immediately after harvest, tubers enter endodormancy and will not produce sprouts when stored at temperatures of $3{ }^{\circ} \mathrm{C}$ or below (Suttle, 2011). Aside from the effects of temperature during the development and storage of tubers (Davidson, 1958), time to sprouting in potato tubers can vary among varieties between years (Kim et al., 1999; Van Ittersum, 1992), by tuber size (Claassens and Vreugdenhil, 2000, Krijthe, 1962; Van Ittersum, 1992), and between species (Hermundstad and Peloquin, 1985; Thompson et al., 1980). Among wild species of tuber-bearing

\begin{tabular}{llll}
\hline $\begin{array}{l}\text { Units } \\
\text { To convert U.S. to SI, } \\
\text { multiply by }\end{array}$ & U.S. unit & SI unit & $\begin{array}{l}\text { To convert SI to U.S., } \\
\text { multiply by }\end{array}$ \\
\hline 29.5735 & $\mathrm{fl} \mathrm{oz}$ & $\mathrm{mL}$ & 0.0338 \\
0.0929 & $\mathrm{ft}^{2}$ & $\mathrm{~m}^{2}$ & 10.7639 \\
2.54 & inch(es) & $\mathrm{cm}$ & 0.3937 \\
25.4 & inch $(\mathrm{es})$ & $\mathrm{mm}$ & 0.0394 \\
28.3495 & $\mathrm{oz}$ & $\mathrm{g}$ & 0.0353 \\
1 & $\mathrm{ppm}$ & $\mu \mathrm{g} \cdot \mathrm{mL}^{-1}$ & 1 \\
$\left({ }^{\circ} \mathrm{F}-32\right) \div 1.8$ & ${ }^{\circ} \mathrm{F}$ & ${ }^{\circ} \mathrm{C}$ & $\left({ }^{\circ} \mathrm{C} \times 1.8\right)+32$
\end{tabular}


Solanum species, the tuber dormancy length can range from a short period such as $20 \mathrm{~d}$ (Thompson et al., 1980) to up to 8 years (Bamberg, 2010).

At the time of sprouting, the tuber becomes repurposed from a storage organ to a source organ for newly developing sprouts (Sonnewald, 2001). Premature potato tuber sprouting during storage can lead to decreased crop values and loss of quality due to remobilization of starch and proteins (Börnke et al., 2007), whereas delayed sprouting after planting can lead to reduced yields (Gandarillas and Nylund, 1949). To simultaneously evaluate populations of tuber-bearing Solanum species for rooting or tuber traits, uniform breaking of tuber dormancy is required. Literature discussing breaking physiological dormancy in tubers suggested using gibberellic acid $\left(\mathrm{GA}_{3}\right)$ (Brian et al., 1955; Galun, 2010; Jansky and Hamernik, 2014; Rappaport, 1956; Rappaport et al., 1957; Sasani et al., 2009) or a combination of ethylene gases (ethylene chlorohydrin, 1,2-dichloroethane, and carbon tetrachloride at the 7:3:1 proportion), often referred to as rindite (Bryan, 1989; Kim et al., 1999; McDonald and Coleman, 1988). The major issue with rindite is the toxicity of the three components. When they are mixed together, rindite creates high toxicity risks for the workers handling the chemicals and the environment (Hansen et al., 2002). Limited information regarding breaking dormancy exists for $S$. chacoense. The objective of this study was to determine an appropriate $\mathrm{GA}_{3}$ concentration and soak time treatment to encourage sprout development across four accessions of $S$. chacoense.

\section{Materials and methods}

Plant material and growth conditions. Eleven $S$. chacoense clones across four accessions were selected for a seed nursery at the U.S. Department of Agriculture (USDA) Agricultural Research Station in Beltsville, MD. The accessions were previously obtained from the USDA Potato Genebank in Sturgeon Bay, WI. Accessions A (PI 275136; clones A-3, A-5, and A-6) and B (PI 320288; clones B-3, B-5, and B-10) originated from Argentina. Accessions C (PI 537025; clones C-6 and C-8) and D (PI 566738; clones D-6, D-7, and D-8) originated from Bolivia and Paraguay, respectively. These clones were selected based on tuber availability and the ability to tuberize in pots. Tubers were cultivated from tuberlings in 6-inch-diameter containers using peatmoss potting mixture (ProMix Flex; Premier Tech Horticulture, Delson, QC, Canada) under a 12-h photoperiod and fertilized using $24 \mathrm{~N}-3.5 \mathrm{P}-13.3 \mathrm{~K}$ water-soluble fertilizer (MiracleGro All-Purpose Fertilizer; Scotts, Marysville, $\mathrm{OH}$ ). Tubers were harvested on 1 Oct. 2013 at the USDA facility in Beltsville, MD, and shipped overnight to the University of Florida in paper bags.

EXPERIMENTAL TREATMENTS. Immediately after arrival, tubers were maintained in complete darkness at $25{ }^{\circ} \mathrm{C}$ for $5 \mathrm{~d}$ after harvest before treatment. A total of 72 tubers of each of the 11 clones were divided evenly into three tuber size classes (small, medium, and large) and exposed to four $\mathrm{GA}_{3}$ concentrations for each of the three desired soak times (12 treatments total). The average fresh weights $( \pm S D)$ were $1.4 \pm 0.03$, $2.6 \pm 0.06$, and $5.6 \pm 0.14 \mathrm{~g}$ for small, medium, and large classes, respectively. The factors were four $\mathrm{GA}_{3}$ concentrations $(0,50,100$, and 150 $\left.\mu \mathrm{g} \cdot \mathrm{mL}^{-1}\right)$, three soak periods $(5,45$, and $90 \mathrm{~min}$ ), tuber size class (small, medium, and large), and accession $(\mathrm{A}, \mathrm{B}, \mathrm{C}$, and $\mathrm{D})$. The concentrated $\mathrm{GA}_{3}$ (Fisher Scientific, Toronto, ON, Canada) was dissolved in distilled deionized (DDI) water at $20^{\circ} \mathrm{C}$ and homogenized for $2 \mathrm{~h}$. Treatments were applied at a rate of 24 tubers in $200 \mathrm{~mL}$ of $\mathrm{GA}_{3}$ solution. Treated tubers were then removed and allowed to air-dry for $3 \mathrm{~h}$ before placement inside two calibrated incubators (MIR-153; Sanyo Electric Co., Moriguchi, Japan) on 6 Oct. 2013 , and maintained at $23{ }^{\circ} \mathrm{C}$. Tubers were periodically removed from the incubators into a lighted room to collect data. To ensure that all tubers were exposed to light for the same length of time, a 12 -h photoperiod was supplied by a fluorescent lamp $\left(15 \mathrm{~W}, 6500{ }^{\circ} \mathrm{K}, 198 \mu \mathrm{mol} \cdot \mathrm{m}^{-2} \cdot \mathrm{s}^{-1}\right)$.

Data collection. The experiment was conducted for $46 \mathrm{~d}$ after treatments (DAT). The number and length of sprouts were determined every $2 \mathrm{~d}$ and summed on a per-tuber basis at the end of the experiment. The number of sprouts per tuber was determined by counting viable sprouts, which was determined as a sprout at least $2 \mathrm{~mm}$ long that showed no signs of desiccation. Time to sprouting was determined as DAT required for the average sprout number (with a minimum length of $2 \mathrm{~mm}$ ) in a single replicate to equal or exceed one. The percentage of sprouted tubers was calculated as the number of tubers sprouted divided by the total number of tubers in that treatment 46 DAT. After 46 DAT, nonsprouted tubers started to shrivel and become desiccated.

Statistical analysis. The experiment was a factorial arrangement of treatments in a completely randomized design with three replicates. An analysis of variance (ANOVA) for each measured variable was conducted using the PROC GLM procedure. Treatments were compared using Tukey-Kramer of the SAS statistical package (version 9.4 for Windows; SAS Institute, Cary, NC).

\section{Results and discussion}

NUMBER OF SPROUTED TUBERS. The ANOVA showed that the $\mathrm{GA}_{3}$ concentration, accession, and tuber size class significantly affected the percentage of sprouted tubers of $S$. chacoense. Application of $\mathrm{GA}_{3}$ significantly increased the number of sprouted tubers. Treatments including 50, 100, and 150 $\mu \mathrm{g} \cdot \mathrm{mL}^{-1} \mathrm{GA}_{3}$ resulted in $48 \%, 40 \%$, and $43 \%$ of sprouted tubers, respectively, whereas the non- $\mathrm{GA}_{3}$ treatment resulted in only $29 \%$ of sprouted tubers at 46 DAT (Fig. 1A). Application of $\mathrm{GA}_{3}$ accelerated sprout formation compared with non- $\mathrm{GA}_{3}$ treatment. The $50 \mu \mathrm{g} \cdot \mathrm{mL}^{-1} \mathrm{GA}_{3}$ resulted in the earliest formation of sprouts at 9 DAT (Fig. 2A). The 100 and $150 \mu \mathrm{g} \cdot \mathrm{mL}^{-1}$ $\mathrm{GA}_{3}$ treatments and $50 \mu \mathrm{g} \cdot \mathrm{mL}^{-1} \mathrm{GA}_{3}$ treatment resulted in similar percentage of tubers sprouted at 19 and 46 DAT. The effect of exogenous $\mathrm{GA}_{3}$ application on sprouting promotion has been previously reported for potato (Alexopoulus et al., 2008), but it has not yet been reported for $S$. chacoense tubers.

There was a significant variation in the percentage of sprouted tubers across the four accessions. The overall percentages of sprouted tubers were $60 \%, 63 \%, 34 \%$, and $3 \%$ for accessions A, B, C, and D, respectively (Fig. 1B). Accession $A$ was the most effective for producing sprouts, with $69 \%$ of tubers sprouted in the absence of $\mathrm{GA}_{3}$, followed by accession B with 38\% 
(Table 1 ). Only $2 \%$ of tubers from accession $\mathrm{C}$ and $6 \%$ of tubers from accession $\mathrm{D}$ produced sprouts in the absence of $\mathrm{GA}_{3}$, indicating a relatively high level of endodormancy. Accessions $\mathrm{A}$ and $\mathrm{B}$ were more effective for producing sprouts earlier in the study, resulting in a greater percentage of tubers sprouted at 19 DAT and for the remainder of the study (Fig. 2B). Accession $\mathrm{C}$ was less effective for producing sprouts, followed by accession $\mathrm{D}$, which produced minimal sprouts 46 DAT (Fig. 2B).

The interaction of $\mathrm{GA}_{3}$ concentration $\times$ accession on the percentage of sprouted tubers at 46 DAT was significant (Table 1). The percentage of sprouted tubers was significantly higher with the application of $\mathrm{GA}_{3}$, regardless of concentration, for accessions $\mathrm{B}$ and $\mathrm{C}$.
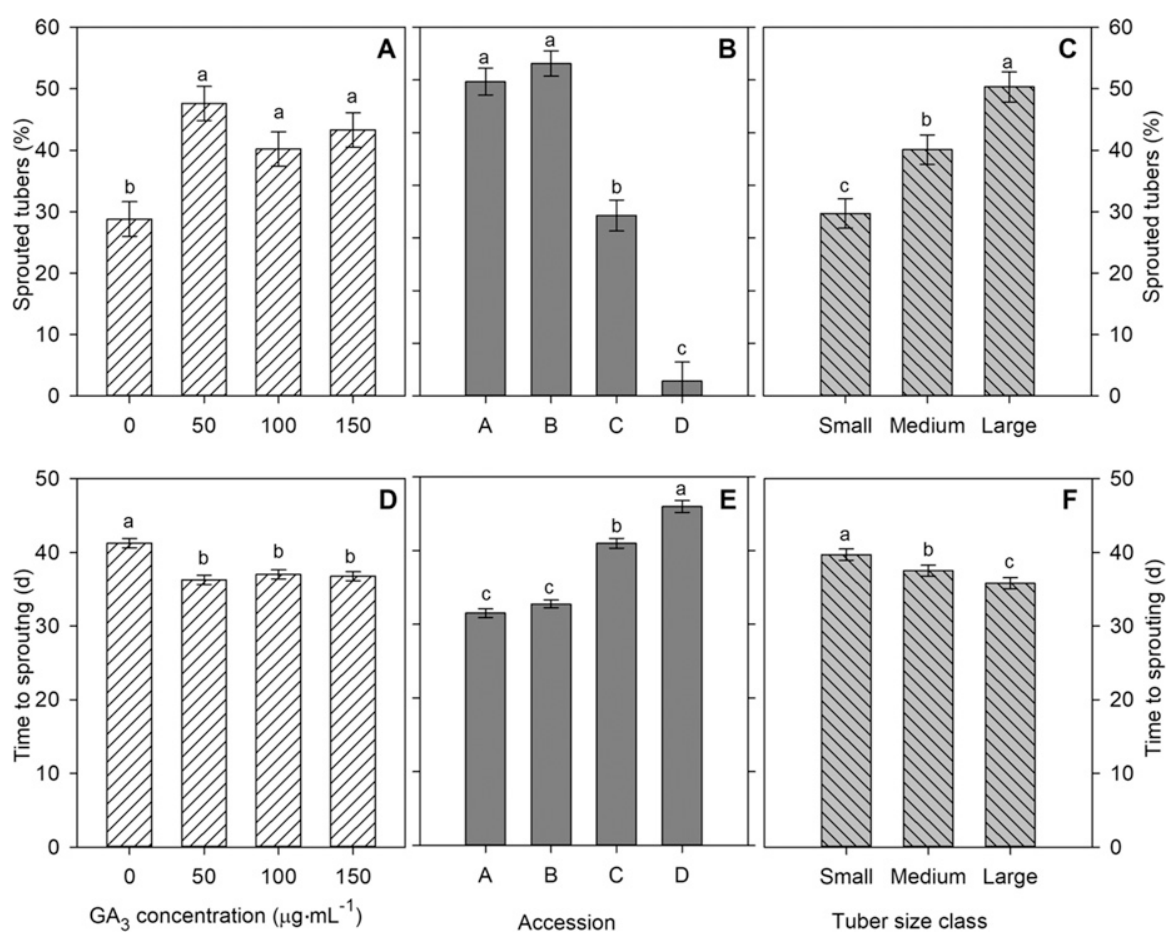

Fig. 1. Main effects of gibberellic acid $\left(G_{3}\right)$ concentrations $(A, D)$, accession (B, $\mathrm{E})$, and tuber size class $(\mathrm{C}, \mathrm{F})$ on the percentage of sprouted tubers $46 \mathrm{~d}$ after treatment and time to sprouting of Solanum chacoense. Tuber size classes were classified according to the average tuber weight as small $(1.5 \mathrm{~g})$, medium $(2.4 \mathrm{~g})$, and large $(5.8 \mathrm{~g})$. Values followed by the same lowercase letter indicate that means are not significantly different at $P<0.05$ according to the Tukey-Kramer test within each graph. Error bars indicate standard error of the mean; $1 \mathrm{~g}=\mathbf{0 . 0 3 5 3} \mathrm{oz}$; $1 \mu \mathrm{g} \cdot \mathrm{mL}^{-1}=1 \mathrm{ppm}$.

Application of 50, 100, and 150 $\mu \mathrm{g} \cdot \mathrm{mL}^{-1}$ of $\mathrm{GA}_{3}$ significantly increased tuber sprouting in $61 \%$ to $77 \%$ and $43 \%$ to $50 \%$ in accessions $\mathrm{B}$ and $\mathrm{C}$, respectively, compared with non- $\mathrm{GA}_{3}$ treatment. There were no significant differences among the 50, 100, and $150 \mu \mathrm{g} \cdot \mathrm{mL}^{-1} \mathrm{GA}_{3}$ treatments on sprouted tubers within accessions, indicating that $50 \mu \mathrm{g} \cdot \mathrm{mL}^{-1}$ of $\mathrm{GA}_{3}$ was a sufficient concentration to break dormancy of three of the four tested accessions of $S$. chacoense. The use of $\mathrm{GA}_{3}$, regardless of concentration, had no effect on the percentage of sprouted tubers for accessions $\mathrm{A}$ and $\mathrm{D}$ due to opposite reasons. Accession D showed a stronger endodormancy mechanism (Table 1 ) and no sensitivity to $\mathrm{GA}_{3}$ treatments, whereas accession $\mathrm{A}$ showed very weak dormancy, producing a similar percentage of sprouted tubers when they were treated or not treated with $\mathrm{GA}_{3}$. The variability of dormancy among potato species and varieties is expected (Bisognin et al., 2018; Brandt et al., 2003; Kim et al., 1999) and, in most of the cases, some variation in the dormancy of tubers can be attributed to the genetic makeup of individuals. Acceleration of breaking dormancy with $\mathrm{GA}_{3}$ has been extensively studied in several potato varieties (Alexopoulos et al., 2008; Hartmann et al., 2011; Van Ittersum, 1992). The present study represents a small proportion of the genetic variability of $S$. chacoenses because only four of the 174 available accessions of $S$. chacoenses from the USDA Potato Genebank were evaluated. The accessions of the present study were selected based on their ability to tuberize in pots and the availability of tubers at harvest. Therefore, much greater variations in
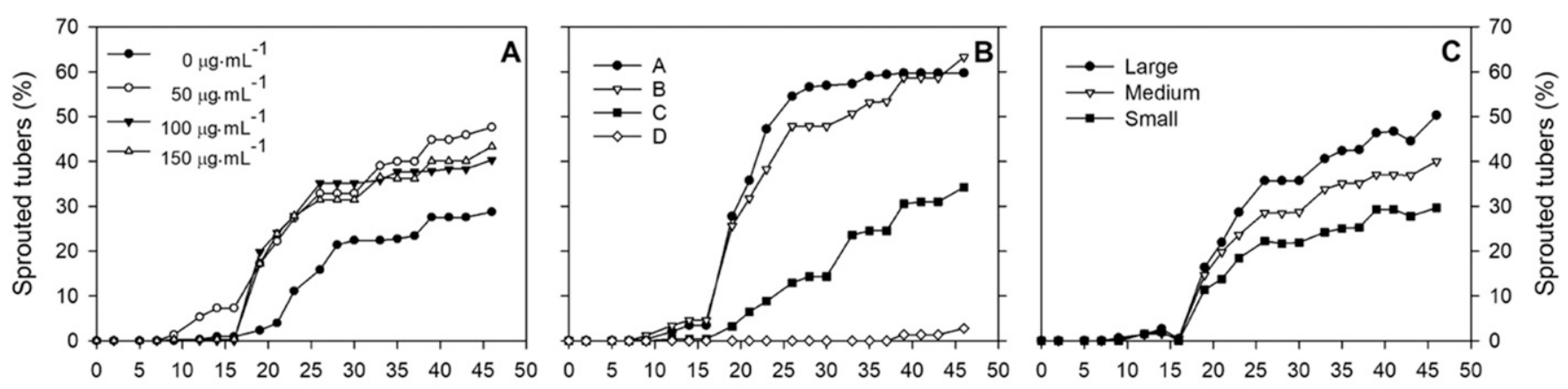

Time after treatment $(d)$

Fig. 2. Main effects of gibberellic acid $\left(\mathrm{GA}_{3}\right)$ concentrations $(\mathrm{A})$, Solanum chacoense accession $(\mathrm{B})$, and tuber size class $(\mathrm{C})$ on the percentage of sprouted tubers of $S$. chacoense. Tuber size classes were classified according to the average tuber weight as small $(1.5 \mathrm{~g})$, medium $(2.4 \mathrm{~g})$, and large $(5.8 \mathrm{~g}) ; 1 \mathrm{~g}=0.0353 \mathrm{oz} ; 1 \mu \mathrm{g} \cdot \mathrm{mL}^{-1}=1 \mathrm{ppm}$. 
Table 1. Interaction between gibberellic acid $\left(\mathrm{GA}_{3}\right)$ concentration treatments and accession of Solanum chacoense on the percentage of sprouted tubers and time to sprouting at $46 \mathrm{~d}$ after treatments.

\begin{tabular}{|c|c|c|c|c|}
\hline \multirow[b]{2}{*}{$\mathrm{GA}_{3}\left(\mu \mathrm{g} \cdot \mathrm{mL}^{-1}\right)^{\mathrm{z}}$} & \multicolumn{4}{|c|}{ S. chacoense accessions } \\
\hline & A & B & $\mathbf{C}$ & D \\
\hline & \multicolumn{4}{|c|}{ Sprouted tubers $[$ mean \pm SE $(\%)]$} \\
\hline 0 & $69.4 \pm 5.1 \mathrm{a}^{\mathrm{y}} \mathrm{A}^{\mathrm{x}}$ & $38.3 \pm 5.4 \mathrm{~b} \mathrm{~B}$ & $1.9 \pm 1.0 \mathrm{~b} \mathrm{C}$ & $5.6 \pm 2.8$ a C \\
\hline 50 & $58.3 \pm 5.1 \mathrm{a} \mathrm{AB}$ & $76.5 \pm 4.8$ a A & $50.0 \pm 6.9$ a B & $5.6 \pm 3.9$ a C \\
\hline 100 & $56.9 \pm 5.9 \mathrm{a} \mathrm{A}$ & $61.2 \pm 5.4 \mathrm{a} \mathrm{A}$ & $42.6 \pm 6.8$ a A & $0.0 \pm 0.0 \mathrm{a} \mathrm{B}$ \\
\hline \multirow[t]{2}{*}{150} & $54.2 \pm 5.9 \mathrm{a} \mathrm{B}$ & $76.5 \pm 4.7$ a A & $42.6 \pm 6.8$ a B & $0.0 \pm 0.0 \mathrm{a} \mathrm{C}$ \\
\hline & \multicolumn{4}{|c|}{ Time to sprouting $[$ mean \pm SE $(d)]$} \\
\hline 0 & $32 \pm 1.3 \mathrm{a} \mathrm{B}$ & $41 \pm 0.9$ a A & $>46 \pm 0.4 \mathrm{a} \mathrm{A}$ & $>46 \pm 0.2 \mathrm{a} \mathrm{A}$ \\
\hline 50 & $31 \pm 1.3 \mathrm{a} \mathrm{B}$ & $29 \pm 1.2 \mathrm{~b} \mathrm{~B}$ & $39 \pm 1.5 \mathrm{~b} \mathrm{~A}$ & $>46 \pm 1.9$ a A \\
\hline 100 & $31 \pm 1.6$ a B & $31 \pm 1.4 \mathrm{~b} \mathrm{~B}$ & $40 \pm 1.2 \mathrm{~b} \mathrm{~A}$ & $>46 \pm 0.0 \mathrm{a} \mathrm{A}$ \\
\hline 150 & $32 \pm 1.6$ a B & $30 \pm 1.3 \mathrm{~b} \mathrm{~B}$ & $39 \pm 1.3 \mathrm{~b} \mathrm{~A}$ & $>46 \pm 0.0 \mathrm{a} \mathrm{A}$ \\
\hline
\end{tabular}

${ }^{\mathrm{z}} 1 \mu \mathrm{g} \cdot \mathrm{mL}^{-1}=1 \mathrm{ppm}$.

${ }^{y}$ Values within columns followed by the same lowercase letter indicate that means are not significantly different at $P<0.05$ according to the Tukey-Kramer test between $\mathrm{GA}_{3}$ concentrations within each $S$. chacoense accession. ${ }^{x}$ Values within rows followed by the same uppercase letter indicate that means are not significantly different at $P<$ 0.05 according to the Tukey-Kramer test between the $S$. chacoense accession within each $\mathrm{GA}_{3}$ concentration.

Table 2. Interaction between tuber size class and accession of Solanum chacoense on sprout length and time to sprouting $46 \mathrm{~d}$ after treatment. Tuber size classes were classified according to the average tuber weight in small $(1.5 \mathrm{~g})$, medium $(2.4 \mathrm{~g})$, and large $(5.8 \mathrm{~g}) .^{\mathrm{z}}$

\begin{tabular}{|c|c|c|c|c|}
\hline \multirow[b]{2}{*}{ Tuber size class } & \multicolumn{4}{|c|}{ S. chacoense accessions } \\
\hline & A & B & $\mathbf{C}$ & $\mathbf{D}$ \\
\hline & \multicolumn{4}{|c|}{ Sprout length $[$ mean \pm SE $(\mathrm{mm})]$} \\
\hline Small & $7.4 \pm 0.9 \mathrm{a}^{\mathrm{z}} \mathrm{A}^{\mathrm{y}}$ & $3.3 \pm 0.5 \mathrm{~b} \mathrm{~B}$ & $3.6 \pm 0.5$ a B & $0.0 \pm 0.0 \mathrm{~b} \mathrm{C}$ \\
\hline Medium & $7.1 \pm 0.7$ a A & $3.7 \pm 0.3 \mathrm{ab} \mathrm{B}$ & $3.5 \pm 0.5$ a B & $0.0 \pm 0.0 \mathrm{~b} \mathrm{C}$ \\
\hline \multirow[t]{2}{*}{ Large } & $6.4 \pm 0.5 \mathrm{a} \mathrm{A}$ & $5.6 \pm 0.4 \mathrm{a} \mathrm{A}$ & $3.5 \pm 0.7 \mathrm{a} \mathrm{B}$ & $3.0 \pm 0.4 \mathrm{a} \mathrm{C}$ \\
\hline & \multicolumn{4}{|c|}{ Time to sprouting $[$ mean \pm SE $(d)]$} \\
\hline Small & $36 \pm 0.9$ a B & $35 \pm 0.9$ a B & $42 \pm 1.1$ a A & $>46 \pm 1.3$ a A \\
\hline Medium & $30 \pm 1.1 \mathrm{~b} \mathrm{~B}$ & $32 \pm 1.0 \mathrm{ab} \mathrm{B}$ & $42 \pm 1.3 \mathrm{a} \mathrm{A}$ & $>46 \pm 1.6$ a A \\
\hline Large & $27 \pm 0.9 \mathrm{~b} \mathrm{D}$ & $31 \pm 0.9 \mathrm{~b} \mathrm{C}$ & $39 \pm 1.1 \mathrm{a} \mathrm{B}$ & $>46 \pm 1.3 \mathrm{a} \mathrm{A}$ \\
\hline
\end{tabular}

${ }^{\mathrm{z}} 1 \mathrm{~g}=0.0353 \mathrm{oz} ; \mathrm{l} \mathrm{mm}=0.0394$ inch.

${ }^{y}$ Values within columns followed by the same lowercase letter indicate that means are not significantly different at $P<0.05$ according to the Tukey-Kramer test between tuber size class within each $S$. chacoense accession.

${ }^{x}$ Values within rows followed by the same uppercase letter indicate that means are not significantly different at $P<$ 0.05 according to the Tukey-Kramer test among $S$. chacoense accessions within each tuber size class.

tuberization and tuber dormancy across different accessions of $S$. chacoense should be expected across all accessions of $S$. chacoense.

The initial separation of tubers into size classes (small, medium, large) significantly affected the percentage of sprouted tubers of $S$. chacoense (Fig. 1C). In the smaller class, $29 \%$ of the tubers had sprouted at 46 DAT; however, in the medium and large tuber classes, $40 \%$ and $50 \%$ of the tubers had sprouted at 46 DAT. Large tubers produced sprouts much earlier than the medium and small classes. Approximately 39\% of the large tubers sprouted at 25 DAT; however, at the same DAT, the percentages of sprouted tubers were $31 \%$ and $24 \%$ for medium and small tuber classes, respectively. The difference in sprouting among tuber size classes was maintained until the end of the study (Fig. 2C). These results corroborate previous research evaluating potato (Claassens and Vreugdenhil, 2000; Van Ittersum, 1992) that indicated that larger tubers exhibited a higher percentage of sprouted tubers earlier in the study.

Soak time had no significant effect on the percentage sprouted tubers of $S$. chacoense. Soak time has been shown to have no effect on the rate or nature of sprouting on potato tubers (Rappaport et al., 1958).

Time to SPROUTING. $\mathrm{GA}_{3}$ concentration, accession, and tuber size class had effects on time to sprouting of $S$. chacoense. Again, the minutes of soak time had no effect on time to sprouting. Overall, treatments with $\mathrm{GA}_{3}$ shortened dormancy by $4 \mathrm{~d}$ (Fig. ID). Under $0 \mu \mathrm{g} \cdot \mathrm{mL}^{-1} \mathrm{GA}_{3}$ treatment, accession $\mathrm{A}$ had the shortest dormancy, only $32 \mathrm{~d}$ to sprout, but there were no significant differences among accessions $\mathrm{B}, \mathrm{C}$, and $\mathrm{D}$, which required more than $4 \mathrm{l} \mathrm{d}$ to sprouting (Table $\mathrm{l}$ ).

There were interactions between $\mathrm{GA}_{3}$ and accession and between accession and tuber size for days required to sprouting. $\mathrm{GA}_{3}$ significantly reduced time to sprouting, regardless of concentration, by an average of $10 \mathrm{~d}$ for accession $\mathrm{B}$ and $7 \mathrm{~d}$ for accession $\mathrm{C}$, but not for accessions A and D. Under the conditions of this study, accession A did not require the application of exogenous $\mathrm{GA}_{3}$ to accelerate or increase the emergence of sprouts. For accessions $\mathrm{B}$ and $\mathrm{C}$, the $50 \mu \mathrm{g} \cdot \mathrm{mL}^{-1}$ concentration of $\mathrm{GA}_{3}$ was sufficient to increase sprouting by $33 \%$ and $41 \%$, respectively. However, for accession $\mathrm{D}$, none of the $\mathrm{GA}_{3}$ concentrations was effective for shortening tuber dormancy. Acceleration of dormancy breaking with the use of $\mathrm{GA}_{3}$ has been reported with doses lower than 50 $\mu \mathrm{g} \cdot \mathrm{mL}^{-1}$ for several potato varieties (Alexopoulos et al., 2008; Hartmann et al., 2011; Van Ittersum, 1992). A practical application of breaking dormancy of potato tubers was demonstrated by Mustefa et al. (2017), who indicated that applications of 10 and $20 \mu \mathrm{g} \cdot \mathrm{mL}^{-1}$ of $\mathrm{GA}_{3}$ on tubers of $B u d u$ significantly reduced the dormancy period from $102 \mathrm{~d}$ for non-treated seed to 83 and $70 \mathrm{~d}$, respectively.

Larger tubers tended to require a shorter time to sprout than smaller tubers (Fig. IF). In accession A, tuber dormancy was significantly shorter in medium and large tubers than in small tubers (Table 2). In accession $\mathrm{B}$, tuber dormancy was significantly shorter in large than in small tubers. In accessions $\mathrm{C}$ and $\mathrm{D}$, tuber size had no effect on tuber dormancy (Table 2).

The effect of tuber size on dormancy has also been observed for potato: smaller tubers required longer periods to produce sprouts and larger tubers exhibited shorter dormancy (Lommen, 1994; Nipa et al., 2013; Van Ittersum, 1992). However, as observed for accessions C and $\mathrm{D}$, there is not always a significant 
and negative correlation between tuber size and the time required to remove dormancy. The absence of a relationship between time to sprouting and tuber size has been reported for some potato varieties (Van Ittersum, 1992).

SPROUT NUMBER AND LENGTH. The $\mathrm{GA}_{3}$ concentration and soak time had no significant effects on sprout number. The sprout number was significantly affected by accession and tuber size only. Accession A had the highest number $( \pm \mathrm{SD})$ of sprouts per tuber $(1.9 \pm 0.1)$; followed by accession B $(1.6 \pm 0.1)$, accession C $(1.6 \pm 0.1)$, and accession $\mathrm{D}(1.0 \pm 0.0)$. The large tuber class produced the highest number of sprouts per tuber $(1.8 \pm 0.1)$, with no significant differences between medium $(1.6 \pm 0.1)$ and small $(1.6 \pm$ $0.1)$ tuber classes.

The $\mathrm{GA}_{3}$ concentrations and accession had significant effects on the sprout length of $S$. chacoense (Table 2). The soak time of $\mathrm{GA}_{3}$ showed no significant effect on sprout length. Without any $\mathrm{GA}_{3}$ treatment, the average sprout length was $3.4 \pm 0.3 \mathrm{~mm}$. The $\mathrm{GA}_{3}$ concentration of $50 \mu \mathrm{g} \cdot \mathrm{mL}^{-1}$ resulted in the longest sprouts $(5.9 \pm$ $0.4 \mathrm{~mm}$ ), which was significantly greater than the sprout length when treated with $100 \mu \mathrm{g} \cdot \mathrm{mL}^{-1}(4.9 \pm 0.4 \mathrm{~mm})$ and $150 \mu \mathrm{g} \cdot \mathrm{mL}^{-1}(5.3 \pm 0.4 \mathrm{~mm})$ of $\mathrm{GA}_{3}$.

Across accessions, accession A produced the longest sprouts $(6.9 \pm$ $0.4 \mathrm{~mm})$, followed by accession B $(4.4 \pm$ $0.3 \mathrm{~mm})$, accession $\mathrm{C}(3.5 \pm 0.3 \mathrm{~mm})$, and accession $\mathrm{D}(2.0 \pm 1.0 \mathrm{~mm})$. There was a significant interaction between accession and tuber size on sprout length (Table 2). Accessions A and C showed no significant effect of tuber size class on the sprout length of $S$. chacoense (Table 2). In accession B, sprout length increased with increasing tuber size. The large tuber class was the only class to produce sprouts in accession $\mathrm{D}$.

These results corroborated previous research that indicated that the application of exogenous $\mathrm{GA}_{3}$ was used to break dormancy and elongate sprouts in several potato varieties (Galun, 2010; Sasani et al., 2009). It is noteworthy that previous research has shown that warm white fluorescents inhibit the elongation of potato sprouts even in the presence of exogenous $\mathrm{GA}_{3}$ (Morris, 1967). Therefore, sprout lengths may have been negatively affected by the presence of artificial lights during the exposure time for the evaluations in this study.

\section{Conclusions}

The effectiveness of $\mathrm{GA}_{3}$ treatments on dormancy breaking of $S$. chacoense was mostly dependent on the accession and tuber size. The accessions used in this study represented a small number of the total number of accessions of $S$. chacoense available in the USDA Potato Genebank, and they exhibited different levels of endodormancy and response to the dormancy breaking treatments. Accessions A and $B$ exhibited weaker dormancy mechanisms overall, whereas accessions C and $\mathrm{D}$ exhibited moderate and strong dormancy mechanisms, respectively.

The $\mathrm{GA}_{3}$ concentration of 50 $\mu \mathrm{g} \cdot \mathrm{mL}^{-1}$ successfully broke tuber dormancy in accessions $\mathrm{B}$ and $\mathrm{C}$; however, for accessions $\mathrm{A}$ and $\mathrm{D}$, there was no difference in time to sprouting due to $\mathrm{GA}_{3}$ treatment. $\mathrm{GA}_{3}$ concentrations more than $50 \mu \mathrm{g} \cdot \mathrm{mL}^{-1}$ showed no increase in the sprouting rate or total percentage of tuber sprouted up to 46 DAT. Future studies should investigate $\mathrm{GA}_{3}$ rates lower than $50 \mu \mathrm{g} \cdot \mathrm{mL}^{-1}$. The soaking time showed no significant effect on breaking dormancy of $S$. chacoense, with 5 min of soaking time being sufficient for breaking dormancy. The tuber size significantly impacted the percentage of sprouting, time to sprouting, and number of sprouts on $S$. chacoense. For those accessions with strong dormancy, alternative methods to break dormancy may be required.

\section{Literature cited}

Alexopoulos, A.A., G. Aivalakis, K.A. Akoumianakis, and H.C. Passam. 2008. Effect of gibberellic acid on the duration of dormancy of potato tubers produced by plants derived from true potato seed. Postharvest Biol. Technol. 49:424-430.

Bamberg, J.B., C.A. Longtine, and E.B. Radcliffe. 1996. Fine screening Solanum (potato) germplasm accessions for resistance to colorado potato beetle. Amer. Potato J. 73:211-223.

Bamberg, J.B. 2010. Tuber dormancy lasting eight years in the wild potato Solanum jamesii. Amer. J. Potato Res. 87:226-228.

Bilski, J.J., D.C. Nelson, and R.L. Colon. 1988. Response of six wild potato species to chloride and sulfate salinity. Amer. Potato J. 65:605-612.

Bisognin, D.A., N.C. Manrique-Carpintero, and D.S. Douches. 2018. QTL analysis of tuber dormancy and sprouting in potato. Amer. J. Potato Res. 95:374-382.

Börnke, F., U. Sonnewald, and S. Biemelt. 2007. Potato, p. 297-315. In: E.C. Pua and M.R. Davey (eds.). Biotechnology in agriculture and forestry. Springer, Heidelberg, Germany.

Brian, P.W., H.G. Hemming, and M. Radley. 1955. A physiological comparison of gibberellic acid with some auxins. Physiol. Plant. 8:899-912.

Bryan, J.E. 1989. Breaking dormancy of potato tubers. CIP Res. Guide 16. Intl. Potato Ctr., Lima, Peru.

Brandt, T.L., G.E. Kleinkopf, N. Olsen, and S.L. Love. 2003. Storage management for Umatilla Russet potatoes. Univ. Idaho Agr. Commun. Bul. 839.

Brown, C.R. and P.E. Thomas. 1993. Resistance to potato leafroll virus derived from Solanum chacoense: Characterization and inheritance. Euphytica 74:5157.

Capo, A., M. Cammareri, F. Delia-Rocca, A. Errico, A. Zoina, and C. Conicella. 2002. Evaluation for chipping and tuber soft rot (Erwinia carotovora) resistance in potato clones from unilateral sexual polyploidization $(2 \mathrm{x} \times 4 \mathrm{x})$. Amer. J. Potato Res. 79:139-145.

Claassens, M.M. and D. Vreugdenhil. 2000. Is dormancy breaking of potato tubers the reverse of tuber initiation? Potato Res. 43:347-369.

Colon, L.T. and D.J. Budding. 1988. Resistance to late blight (Phytophthora infestans) in ten wild Solanum species. Euphytica 39:77-86.

Davidson, T.M.W. 1958. Dormancy in the potato tuber and the effects of storage conditions on initial sprouting and on subsequent sprout growth. Amer. Potato J. 35:451-465.

Errebhi, M., C.J. Rosen, F.I. Lauer, M.W. Martin, J.B. Bamberg, and D.E. Birong. 1998. Screening of exotic potato germplasm for nitrogen uptake and biomass production. Amer. J. Potato Res. 75:93100.

Errebhi, M., C.J. Rosen, F.I. Lauer, M.W. Martin, and J.B. Bamberg. 1999. Evaluation of tuberbearing Solanum species for nitrogen use efficiency and biomass partitioning. Amer. J. Potato Res. 76:143151.

Fernie, A.R. and L. Willmitzer. 2001. Molecular and biochemical triggers of potato tuber development. Plant Physiol. 127:1459-1465.

Galun, E. 2010. Patterning of flowers: Genes and phytohormones, p. 325-366. 
In: E. Galun (ed.). Phytohormones and patterning: The role of hormones in plant architecture. World Scientific, Hackensack, NJ.

Gandarillas, H. and R.E. Nylund. 1949. Further studies on the influence of sprout inhibiting and sprout inducing treatments on the growth and yields of potatoes. Amer. Potato J. 26:7-16.

Hansen, J., Z. Ju, P.D. Petracek, P. Warrior, and D. Woolard. 2002. Promoting early establishment of potato crops by ethylene inhibitors. European Patent Office EP1534069B1. 23 Sept. 2019. <http:// www.google.com/patents/EP1534069Bl? $\mathrm{cl}=\mathrm{en}>$.

Hartmann, A., M. Senning, P. Hedden, U. Sonnewald, and S. Sonnewald. 2011. Reactivation of meristem activity and sprout growth in potato tubers requires both cytokinin and gibberellin. Plant Physiol. 155:776-796.

Hermundstad, S.A. and S.J. Peloquin. 1985. Germplasm enhancement with potato haploids. J. Hered. 76:463-467.

Jackson, S.D. 1999. Multiple signaling pathways control tuber induction in potato. Plant Physiol. 119:1-8.

Jansky, S. and A. Hamernik. 2014. Rapid cycling of potato tuber generations by overcoming dormancy. Amer. J. Potato Res. 92:148-152.

Kim, H.S., J.H. Jeon, K.H. Choi, Y.H. Joung, and H. Joung. 1999. Effects of rindite on breaking dormancy of potato tubers. Amer. J. Potato Res. 76:5-8.

Krijthe, N. 1962. Observations on the sprouting of seed potatoes. Eur. J. Potato Res. 5:316-333.

Leue, E.F. and S.J. Peloquin. 1980. Selection for $2 \mathrm{n}$ gametes and tuberization in Solanum chacoense. Amer. Potato J. 57: 189-195.
Lommen, W.J. 1994. Effect of weight of potato minitubers on sprout growth, emergence and plant characteristics at emergence. Potato Res. 37:315-322.

Lynch, D.R., L.M. Kawchuk, and J. Hachey. 1997. Identification of a gene conferring high levels of resistance to verticillium wilt in Solanum chacoense. Plant Dis. 81:1011-1014.

McDonald, J.G. and W.K. Coleman. 1988. A reevaluation of bromoethane in comparison to rindite for the post-harvest detection of potato virus $\mathrm{Y}$ in tubers by ELISA. Amer. Potato J. 65:547-550.

Morris, D.A. 1967. The influence of light, gibberellic acid and CCC on sprout growth and mobilization of tuber reserves in the potato (Solanum tuberosum L.). Planta 77:224-232.

Mustefa, G., W. Mohammed, N. Dechassa, and D. Gelmesa. 2017. Effects of different dormancy-breaking and storage methods on seed tuber sprouting and subsequent yield of two potato (Solanum tuberosum L.) varieties. Open Agr. 2:220 229.

Mweetwa, A.M., D. Hunter, R. Poe, K.C. Harich, I. Ginzberg, R.E. Veilleux, and J.G. Tokuhisa. 2011. Steroidal glycoalkaloids in Solanum chacoense. Phytochemistry 75:3240.

Nipa, J.S., T.S. Roy, A.K. Amin, and M.R. Hasanuzzaman. 2013. Effect of lifting time and tuber size on ambient storage performance of potato derived from true potato seed. Intl. J. Sustainable Agr. 5:1-

Rappaport, L. 1956. Growth regulating metabolites. Calif. Agr. 10(12):7-11.

Rappaport, L., L.F. Lippert, and H. Timm. 1957. Sprouting, plant growth, and tuber production as affected by chemical treatment of white potato seed pieces. Amer. Potato J. 34:254-260.

Rappaport, L., H. Timm, and L.F. Lippert. 1958. Gibberellin on white potatoes. Calif. Agr. 12(2):4-6.
Sasani, R., H.R. Khazaee, and A. Nezami. 2009. Effect of gibberellin, benzyl adenine, zeatin and temperature on mini tuber dormancy breaking. J. Hort. Sci. 23:61-67.

Sato, M., K. Nishikawa, K. Komura, and K. Hosaka. 2006. Potato virus Y resistance gene, $R y_{c b c}$, mapped to the distal end of potato chromosome 9. Euphytica 149:367-372

Shewry, P.R. 2003. Tuber storage proteins. Ann. Bot. 91:755-769.

Sinden, S.L., L.L. Sanford, and S.F. Osman. 1980. Glycoalkaloids and resistance to the colorado potato beetle in Solanum chacoense Bitt. Amer. Potato J. 57:331-343.

Sonnewald, U. 2001. Control of potato tuber sprouting. Trends Plant Sci. 6:333335 .

Suttle, J.C. 2011. Dormancy and sprouting, p. 288-308. In: D. Vreugdenhil, J. Bradshaw, C. Gebhardt, F. Govers, M. Taylor, D. MacKerron, and H. Ross (eds.). Potato physiology and biotechnology. Advances and perspectives. Elsevier, New York, NY.

Thompson, P., F. Haynes, and R. Moll. 1980. Estimation of genetic-variance components and heritability for tuber dormancy in diploid potatoes. Amer. Potato J. 57:3946.

Uribe, P., S. Jansky, and D. Halterman. 2014. Two CAPS markers predict verticillium wilt resistance in wild Solanum species. Mol. Breed. 33:465-476.

Van Ittersum, M.K. 1992. Variation in the duration of tuber dormancy within a seed potato lot. European Potato J. 35:261-269.

Xu, X., A.A.M. Van Lammeren, E. Vermeer, and D. Vruegdenhil. 1998. The role of gibberellin, abscisic acid, and sucrose in the regulation of potato tuber formation in vitro. Plant Physiol. 117:575-584. 